\title{
BAHASA SEBAGAI ALAT KOMUNIKASI PUBLIK DAN PEMBANGUNAN WACANA
}

\author{
Mudjia Rahardjo \\ Pembantu Rektor Bidang Akademik, Dosen Jurusan Bahasa dan Sastra Inggris, \\ Fakultas Humaniora dan Budaya, Universitas Islam Negeri (UIN) Malang. \\ Jalan Gajayana No. 50 Telepon (0341) 551354, Faksimile (0341) 572533 Malang 65144
}

\begin{abstract}
Language is the most important tool we have for effective human communication, and the efficacy of communication is therefore directly related to the quality of this oral communication medium. The effectiveness of communication depends on several factors, the most important of which are the contents of the communication, the parties involved in the communication and the setting in which the communication takes place. Bad communication can lead to a complete breakdown in relationship and cause misunderstandings which quite often lead to conflicts between elements in the social structure. Effective communication has a very important role in creating an environment for reasoned debat, discussion and understanding in global society, and in this regard the current American approach to creating conducive to reasoned debate on the issue of global terrorisme is hypothesized to be in the less-than-effective category.
\end{abstract}

\section{Key words}

Human, Communication, Discource

\section{Pengantar}

Salah satu hal yang memungkinkan manusia membangun peradabannya adalah bahasa. Bahasa mempunyai kedudukan yang 
sangat penting. Kita bisa bayangkan apa yang terjadi jika manusia tidak mempunyai bahasa. Bahasalah yang memungkinkan manusia hidup dan berkembang sebagaimana yang dapat kita saksikan hingga saat ini. Tidaklah berlebihan jika dikatakan bahwa bahasa ibarat udara yang setiap saat dibutuhkan manusia bagi kehidupannya.

Pun sebaliknya. Di mana ada manusia, di sana ada bahasa. Keduanya tidak dapat dipisahkan. Bahasa tumbuh dan berkembang karena manusia. Manusia berkembang juga karena bahasa. Keduanya menyatu dalam segala aktivitas kehidupan. Hubungan manusia dan bahasa merupakan dua hal yang tidak dapat dinafikan salah satunya. Bahasa pula yang membedakan manusia dari mahluk ciptaan Tuhan yang lain.

Bahasa merupakan warisan manusia yang sangat berharga sepanjang sejarah kehidupannya. Warisan kebahasaan ini sangat berbeda dengan warisan lain seperti harta benda, monumen-monumen dan warisan kebendaan lainnya. Bahasa adalah warisan hidup bagi manusia. Sebagai warisan hidup manusia bahasa harus dipelajari. Seorang anak manusia tidak akan pernah bisa berbahasa jika kepadanya tidak diajari bahasa.

Pada kesempatan ini, saya ingin memberikan beberapa pemikiran yang berkenaan dengan bahasa dalam kaitannya dengan pembangunan wacana. Secara sistematis pembahasan ini akan mencakup hal-hal sebagai berikut: 1) manusia dan bahasa, 2) bahasa dan komunikasi, dan 3) bahasa dan pembangunan wacana.

\section{Manusia dan Bahasa}

Salah satu hal yang sering disebut adalah bahwa manusia bereksistensi sebagai mahluk sosial (zoon politicon) di samping eksistensinya sebagai mahluk ekonomi (homo economicus), mahluk yang berakal (zoon logon echon) dan sebagainya. Penyebutan manusia sebagai mahluk sosial didasarkan pada kenyataan bahwa manusia memerlukan pihak lain di dalam memenuhi kebutuhannya. 
Abraham Maslow (Djalali, tt:18) menjelaskan bahwa terdapat 5 (lima) hierarkhi kebutuhan manusia, yaitu: 1) kebutuhan fisiologis (basic needs), 2) kebutuhan rasa aman (safety needs), 3) kebutuhan rasa cinta dan memiliki (love and belonging needs), 4) kebutuhan akan harga diri (self esteem needs), dan 5) kebutuhan aktualisasi diri (self actualization needs). Kalau kita mengacu pada pemikiran Maslow di atas, dapat dipastikan bahwa dari semua kebutuhan manusia hampir tidak dapat dicapai tanpa keterlibatan pihak lain. Bagaimana mungkin manusia dapat memenuhi kebutuhan dasarnya (basic needs) seperti makan, minum, pakaian, tempat tinggal, dan sebagainya tanpa ada peran serta pihak lain? Bagaimana mungkin manusia dapat memenuhi kebutuhannya dalam beraktualisasi dan mendapatkan pengakuan diri dengan hanya mengandalkan dirinya sendiri? Pun juga dengan kebutuhan-kebutuhan lainnya. Tidak ada satupun dalam pemenuhan kebutuhan-kebutuhan tersebut yang dapat abai dengan pihak lain.

Didorong kondisi tersebut, manusia memerlukan interaksi dengan pihak lain. Dalam konteks inilah bahasa memainkan peran penting, karena melalui bahasa manusia dapat berkomunikasi dalam interaksinya dengan orang lain. Adalah sesuatu yang sangat sulit, untuk tidak mengatakan mustahil, dilakukan jika manusia dalam berinteraksi dan berkomunikasi tanpa melibatkan unsur bahasa. Tidaklah berlebihan jika Bourdie (Rusdiarti, 2003:34) misalnya mengatakan bahwa fungsi utama bahasa adalah sebagai alat komunikasi di samping juga memainkan fungsi-fungsi lainnya.

Memang harus diakui bahwa fungsi komunikasi hanyalah salah satu fungsi utama yang dimiliki bahasa dan masih terdapat fungsi bahasa yang lain. Sebagaimana dijelaskan Hymes (Suprapto, 1989) bahwa dalam konteks sosial, bahasa mempunyai fungsi sebagai potret kenyataan sosial dan sarana untuk menunjukkan identitas sosial-budaya (representation function). Bagi mereka yang bergerak aktif di bidang sosiolinguistik, sangat disadari bahwa bahasa dan kenyataan sosial merupakan satu kesatuan. Karenanya, budaya berkomunikasi sekelompok orang atau masyarakat dapat dijadikan representasi kondisi sosial yang ada. Di Era Reformasi, misalnya, di mana budaya 
transparansi dan euphoria demokrasi menjadi hal yang niscaya, kita saksikan tumbuhnya budaya interupsi dan kekurangsantunan berbahasa dalam komunikasi di kalangan elit politik yang tidak kita saksikan di masa-masa lalu.

Berbahasa merupakan aktivitas rutin yang mesti dialami setiap manusia dan bahkan menjadi bagian integral kehidupan manusia sehari-hari tanpa kecuali, sejalan dengan keadaan manusia sebagai mahluk sosial. Sebagai mahluk sosial, manusia membutuhkan bersosialisasi dan mengembangkan kebudayaannya dengan yang lain. Dalam bersosialisasi dan berkebudayaan ini bahasa sangat diperlukan.

\section{Bahasa dan Komunikasi}

Sebagaimana dijelaskan di atas, bahasa mempunyai kaitan yang erat dalam proses komunikasi. Tidak ada satu peristiwa komunikasipun yang tidak melibatkan bahasa. Komunikasi pada hahekatnya adalah proses penyampaian pesan dari pengirim kepada penerima. Hubungan komunikasi antara pengirim dan penerima, dibangun berdasarkan penyusunan kode atau simbol bahasa oleh pengirim (chiffrement) dan pembongkaran kode atau simbol bahasa oleh penerima (dechiffrement) (Rusdiarti, 2003:35). Lebih jelasnya lihat bagan berikut:
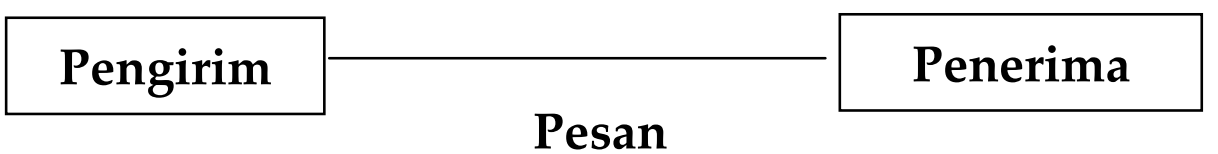

Mengingat kenyataan bahwa dalam berkomunikasi kita dihadapkan oleh varian penerima yang sangat beragam, maka keberhasilan komunikasi akan sangat ditentukan oleh bagaimana cara kita menyampaikan pesan. Tidak jarang dalam kenyataan sehari-hari kita dapati bahwa komunikasi yang kita lakukan tidak berhasil akibat ketidaktepatan cara berkomunikasi yang kita lakukan. Wardhaugh dalam bukunya An Introduction to Sociolinguistics (1986) menjelaskan bahwa ketika orang akan mulai berbicara paling tidak ada tiga hal yang 
mesti diperhatikan agar komunikasinya berlangsung efektif. Pertama, apa yang akan dibicarakan. Kedua, dengan siapa dia akan bicara, dan ketiga, bagaimana cara membicarakannya. Dalam hal ini terkait dengan pemilihan ragam bahasanya, jenis kalimat, kosa kata, bahkan tinggi rendahnya suara saat berbicara. Keputusan mengenai mana yang akan dipakai sangat tergantung pada sejauh mana hubungan sosial dengan lawan bicara.

Lebih lanjut, Badudu dalam bukunya Inilah Bahasa Indonesia yang Benar (1995) menjelaskan berbahasa yang efektif ialah berbahasa yang sesuai dengan lingkungan di mana bahasa itu digunakan. Menurutnya, ada beberapa faktor yang harus diperhatikan yaitu: 1) orang yang berbicara, 2) orang yang diajak bicara, 3) situasi pembicaraan apakah formal atau non-formal (santai), dan 4) masalah yang dibicarakan (topik).

Seorang Presiden yang sedang berdiri di depan forum resmi, tentulah harus menggunakan bahasa formal (bahasa baku). Demikian juga seorang guru yang sedang berdiri di depan kelas menyampaikan pelajaran kepada para muridnya atau seorang dosen yang memberikan kuliah kepada mahasiswanya. Hal ini mesti dilakukan karena situasinya adalah situasi formal. Seorang presiden ketika berada dalam forum resmi tentunya tidak tepat jika menggunakan ragam bahasa santai, misalnya dengan menggunakan dialek lokal.

Demikian juga, seorang kuli bangunan di Surabaya, misalnya, yang sedang bercakap-cakap dengan temannya sesama kuli, tentu menggunakan ragam bahasa seperti yang biasa mereka gunakan. Bahasa mereka tentu bukan bahasa baku, tetapi ragam bahasa santai dan dengan dialek lokal yang kental seperti peno, koen, rek, untuk mengganti anda atau saudara.

Kalau seorang ilmuwan bercakap dengan temannya sesama ilmuwan dan yang dibicarakan adalah tentang sesuatu yang menyangkut suatu ilmu, tentu harus menggunakan bahasa baku (bahasa ilmiah). Demikian halnya kalau kita pergi ke pasar dan sedang melakukan transaksi jual beli, tentunya kita akan menggunakan ragam 
bahasa santai sesuai dengan dialek yang digunakan dalam masyarakat itu. Kalau seorang anak akan berangkat ke kantor dan berpamitan kepada orang tuanya, tentulah bahasa santai dan informal yang digunakan. Perhatikan contoh dialog berikut:

Anak : Bapak dan Ibu yang saya hormati. Saya pagi ini akan
berangkat ke kantor. Untuk itu saya mohon do'a
semoga saya selalu berada dalam lindungan Tuhan
sehingga selamat pada saat berangkat dan pulang.
Orang tua : Anakku yang saya cintai. Silakan berangkat. Engkau
anak yang baik. Saya sebagai orang tua selalu berdoa
semoga engkau selamat sampai nanti kembali ke
rumah.

Jika komunikasi model seperti di atas benar-benar berlangsung, maka betapa sulit dan kakunya hubungan antara anak dan orang tua tersebut. padahal sebagai sarana komunikasi, bahasa hadir untuk memudahkan komunikasi di antara pemakainya. Kerena itu, sekalipun bahasa tersebut cocok dengan situasinya, tetapi ragamnya tidak cocok.

Menurut Burke dalam berkomunikasi manusia cenderung memilih kata-kata tertentu untuk mencapai tujuannya (Eriyanto, 2000). Pemilihan kata-kata tersebut bersifat strategis. Dengan demikian, kata yang diucapkan, simbol yang diberikan, dan intonasi pembicaraan tidaklah semata-mata sebagai ekspresi pribadi atau cara berkomunikasi, tetapi dipakai dengan sengaja untuk maksud tertentu.

Berkenaan dengan hal di atas, pemilihan kosa kata terutama untuk dialog yang melibatkan dua kebudayaan yang berbeda adalah hal penting untuk diperhatikan dalam berkomunikasi. Sebagai contoh adalah kosa kata mari dalam bahasa Jawa yang mempunyai pengertian selesai, tetapi kata ini memiliki penggunaan yang berbeda di beberapa daerah. Di Yogjakarta misalnya, kata ini tepat digunakan untuk menyatakan sembuh dari sakit, sedangkan bagi masyarakat Malang dan 
Surabaya, misalnya, kata ini dapat digunakan untuk menunjuk pada selesainya pekerjaan.

$$
\begin{array}{cc}
\text { Yogjakarta } & : \text { Wis mari tugasmu? (tidak tepat) } \\
& \text { Wis rampung tugasmu? (tepat) } \\
\text { Malang } & : \text { Tiba'e wis mari lorone! (tepat) } \\
& \text { Wis mari tugasmu? (tepat) }
\end{array}
$$

Meminjam pakar hermeneutika Gadamer (1977) bahwa ada makna tersembunyi ketika orang berkomunikasi yang saling dipahami (hidden communication). Itulah sebabnya, hal lain yang penting diperhatikan adalah memahami konteks pembicaraan. Sejauhmana hidden communication dapat dipahami itulah yang menentukan efektivitas dan keberhasilan dalam berkomunikasi. Tidaklah berlebihan jika Suparno (2000) menjelaskan bahwa komunikasi yang berhasil adalah komunikasi yang berbekal kemampuan menyimpulkan apa yang dilakukan oleh partisipan terhadap bentuk bahasa dan konteks penggunaannya. Karena budaya kita berkomunikasi cenderung menggunakan tindak tutur tidak langsung (indirect speech act), maka perlu kemampuan menarik kesimpulan yang tepat dari apa yang dibicarakan.

Berdasarkan penjelasan di atas, kita dapat mengambil pemahaman bahwa ketidakberhasilan dalam berkomunikasi disebabkan oleh beberapa hal, yaitu: 1) kekurangmampuan menarik kesimpulan dalam proses komunikasi, 2) ketidaktepatan pemilihan kosa kata, 3) kekurangcermatan dalam melihat konteks dan situasi komunikasi; dan 4) ketidakefektivan dalam berbahasa baik yang mencakup siapa mitra bicara, apa topik pembicaan dan bagaimana cara berkomunikasi.

Ketidakberhasilan dalam berkomunikasi inilah yang dalam banyak hal telah menimbulkan masalah dan bahkan konflik. Masih hangat dalam ingatan kita bagaimana konflik yang terjadi antara Dewan Perwakilan Rakyat dengan Presiden Abdurrahman Wahid beberapa tahun lalu. AlHumani dalam tulisannya di Harian Umum Kompas 
Hilangnya Jiwa kenegarawanan (2000) memberikan analisis bahwa konflik yang terjadi antara elit di Senayan dan Istana Negara dipicu oleh adanya "kesalahan" dalam komunikasi. Dalam hal ini disebabkan oleh Gus Dur yang cenderung obral pernyataan kontroversial, liar dan cenderung sarkastik. Kata-kata seperti maling, biang keraok, DPR seperti Taman Kanak-Kanak, dan sebagainya adalah kata-kata yang kurang tepat dan cenderung bersifat sarkastik terlebih jika diucapkan seorang Presiden.

Dalam kapasitasnya sebagai presiden, tentu setiap tindakan dan ucapan Gus Dur berdampak besar dalam kehidupan sosial-politik dan ekonomi. Menurut Bourdie (1994) kekuatan kata atau ucapan tidak sekedar terletak pada kata dan ucapan itu sendiri, tetapi pada siapa yang mengucapkannya.

\section{Bahasa dan Pembangunan Wacana}

Dalam perspektif Bourdie, informasi dapat diterima dalam hubungan komunikasi antara pengirim dan penerima dikonstruksi dari proses penyusunan simbol-simbol bahasa oleh pengirim dan pembongkaran/pemahaman simbol-simbol bahasa oleh penerima. Keberhasilan pertukaran bahasa dalam hubungan komunikasi tidak hanya berhenti dan ditentukan oleh peristiwa komunikasi itu sendiri, tetapi juga sangat dipengaruhi oleh konteks sosial dan pasar linguistik yang sedang bekerja.

Dalam konteks pembentukan wacana, wacana yang dikirim bukanlah sekedar pesan yang diharapkan dapat dipahami penerima. Sebuah wacana juga merupakan kumpulan tanda dan simbol yang bertujuan untuk dinilai dan diapresiasi atau bertujuan untuk dipercaya dan dipatuhi. Hal yang terakhir inilah yang menunjukkan otoritas yang ingin dicapai oleh pengirim. Otoritas adalah bentuk kekuasaan tertinggi (kekuasaan simbolik).

Bourdie membuat topologi arena sosial sebagai arena pertarungan wacana, antara wacana dominan (doxa) dengan wacana lain yang menggugatnya. Bourdie dalam hal ini membuat analogi arena pertarungan wacana sebagaimana pertarungan dalam medan sosial, 
yaitu: adanya kekuatan dominan dan marginal. Wacana dominan akan terus mempertahankan dominasinya, sedangkan yang marginal akan berusaha terus menggugatnya.

Doxa adalah wacana yang kita terima begitu saja sebagai kebenaran dan telah menjadi mainstream. Ia biasanya tidak pernah kita pertanyakan lagi sebab-sebabnya, bahkan kebenarannya. Bentuk doxa dapat berupa kebiasan yang sederhana seperti cara duduk, makan, sampai hal yang lebih luas seperti ideologi dan kepercayaan. Dalam kenyataan, medan wacana terus bergerak dinamis. Pertarungan antara heterodoksa dan ortodoksa senantiasa terus berlangsung. Heterodoksa adalah wacana yang berseberangan dengan wacana dominan. Ortodoksa adalah wacana yang mendukung dan mempertahankan wacana dominan. Mereka senantiasa saling berdialog dan bersaing untuk memperebutkan posisi.

Dalam konteks inilah sebenarnya fungsi keberhasilan dalam berkomunikasi memiliki kedudukan yang sangat signifikan. Wacanawacana yang bersifat heterodoksa bisa jadi akan menggantikan wacana yang bersifat ortodoksa. Seringkali kegagalan dalam mempertahankan wacana dominan (doxa) adalah karena kegagalan dalam berkomunikasi. Dalam hal ini barangkali dapat kita ambil contoh kasus berikut: Pertama, pada masa-masa awal reformasi, Gus Dur di awal kepemimpinannya di anggap sebagai "Dewa" penolong dan taruhan harapan dalam memperjuangkan demokratisasi dan perbaikan kondisi bangsa yang sedang dilanda krisis. Namun, pada akhirnya wacana ini dikalahkan oleh wacana heterodoksa tentang otoritarianya, arogansinya dan kekeraskepalaannya dalam memimpin. Hal ini terjadi karena kegagalannya dalam berkomunikasi. Kedua, ortodoksa yang dilancarkan Amerika Serikat dalam persoalan senjata pemusnah massal (mass destruction weapon) yang dimiliki pemerintahan Saddam Hussein, dalam kenyataannya belum dapat mengalahkan heterodoksa perihal kebohongan informasi yang dilakukan agen-agen CIA tentang keberadaan senjata tersebut. Hal ini dapat terjadi karena kejelian, kecermatan, dan keberhasilan dalam berkomunikasi. Keberhasilan komunikasi inilah yang kemudian mempengaruhi opini di masyarakat. 


\section{Penutup}

Adalah penting dalam organisasi untuk menguasai cara berkomunikasi yang tepat dan benar. Ketepatan dan kebenaran dalam berkomunikasi sangat menentukan keberhasilan dalam berkomunikasi. Keberhasilan dalam berkomunikasi adalah langkah awal menuju kesuksesan karena dengan keberhasilan dalam berkomunikasi kita akan dapat menghindari kegagalan dalam berkomunikasi yang dapat menyebabkan kesalahpahaman (misunderstanding). Kesalahpahaman inilah yang dalam banyak fakta merupakan awal dari terciptanya sebuah malapetaka, kehancuran dan konflik.

Demikian halnya dalam konteks pembentukan wacana, keberhasilan dalam berkomunikasi adalah keniscayaan. Tanpa komunikasi yang berhasil mustahil sebuah organisasi mampu membentuk wacana dan bahkan lebih jauh lagi menciptakan doxa. Apalagi dalam iklim sekarang yang sarat dengan pertarunganpertarungan simbolik yang semakin meningkat seiring dengan peningkatan media komunikasi. $\square$

\section{DAFTAR PUSTAKA}

Alhumani, Amich. 2000, 10 Juli. "Hilangnya Jiwa Kenegarawanan", Kompas.

Badudu. 1995. Inilah Bahasa Indonesia yang Benar. Jakarta: PT. Gramedia Pustaka Utama.

Bourdie, Piere. 1994. Language and Symbolic Power. Cambridge Massachusetts: Harvard University Press. 
Djalali, As'ad. Tanpa tahun. Psikologi Motivasi. Surabaya: PPS Psikologi Universitas Tujuh Belas Agustus Surabaya.

Eriyanto. 2000. Kekuasaan Otoritas dari Gerakan Penindasan Menuju Politik Hegemoni: Studi atas Pidato-pidato Politik Soeharto. Yogyakarta: Pustaka Pelajar.

Gadamer. 1977. Philosophical Hermeneutics. Berkeley Los Angeles, London: University of California.

Rusdiarti, Suma Riella. 2000. "Bahasa, Pertarungan Simbolik dan Kekuasaan", dalam BASIS November-Desember.

Suparno. 2000, 18 April. "Wacana dalam Bahasa Cenderung Paradoksal".Kompas.

Suprapto, Riga Adiwoso. 1989. "Perubahan Sosial dan Perkembangan Bahasa", dalam Prisma, No. 1 Tahun XVII.

Wardhaugh. 1986. An Introduction to Sociolinguistics. Oxford: Basil Blackwell Ltd. 